\title{
Investigation of Ocean Surface Wave Refraction Using TerraSAR-X Data
}

\author{
Xiaoming Li, Susanne Lehner, and Wolfgang Rosenthal
}

\begin{abstract}
As a scientific and technological continuation of the X-band Synthetic Aperture Radar (X-SAR) and Shuttle Radar Topography Mission (SRTM) missions, the new X-SAR, namely, TerraSAR-X (TSX), was launched on June 15, 2007. Since then, it has provided numerous high-quality data over land and ocean operationally. In this paper, surface wave refraction and diffraction are investigated using TSX imagery acquired over the coast of Terceira island situated in the North Atlantic. Peak wavelength and wave direction are determined by SAR 2-D image spectra. They are compared to measurements of $\mathrm{X}$-band marine radar and results of the WAve prediction Model (WAM). Significant wave height in the near-shore shallow water region is estimated from TSX Spotlight mode data following the wave refraction laws and using the developed XWAVE empirical algorithm. Image spectra of the TSX subscenes in the full-coverage region are given to investigate significant changes of wave direction and length. By analyzing another TSX image acquired in StripMap mode, a shadow zone in the lee side of Terceira island is identified. It is influenced jointly by wave refraction and diffraction. Furthermore, a cross-sea pattern revealed in the image spectra is investigated. The cross sea is generated by the diffracted wave rays from the northern and southern coasts of the island. Less wave directional spreading for the cross-sea situation is observed as well when compared to the image spectra at the origin of diffraction.
\end{abstract}

Index Terms-Cross sea, refraction and diffraction, sea surface wave, synthetic aperture radar (SAR).

\section{INTRODUCTION}

$\mathbf{S}$ URFACE waves are the most obvious ocean surface features. Mechanisms of synthetic aperture radar (SAR) ocean wave imaging, interpretations of coastal wave behavior, and inversions of 2-D ocean wave spectral have been studied since the L-band SAR sensor onboard SEASAT was launched in 1978. For the first time, the SEASAT SAR provided globally 2-D ocean wave observations from space [1] through clouds and independent of illumination by sunlight. Theoretical models for SAR imaging of ocean surface waves are described in, e.g., [2] and [3]. On this basis, schemes to derive 2-D ocean wave spectra from SAR data have been developed and routinely operated at weather service centers [4]-[9].

Manuscript received February 28, 2009; revised July 9, 2009 and August 14, 2009. First published November 13, 2009; current version published January 20,2010 . This work was supported in part by the TerraWAM project funded by the German Aerospace Center (DLR) under Grant 50EE0729.

$\mathrm{X}$. Li and $\mathrm{S}$. Lehner are with the Remote Sensing Technology Institute, German Aerospace Center (DLR), 82234 Wessling, Germany (e-mail: Xiao.Li@dlr.de; Susanne.Lehner@dlr.de).

W. Rosenthal is with GAUSS mbH, 28199 Bremen, Germany (e-mail: wr@gauss.org).

Color versions of one or more of the figures in this paper are available online at http://ieeexplore.ieee.org.

Digital Object Identifier 10.1109/TGRS.2009.2033177
TABLE I

IMAGING CHARACTERISTICS OF TSX IN DIFFERENT MODES

\begin{tabular}{|c|c|c|c|c|}
\hline & ScanSAR & StripMap & Spotlight & HR Spotlight \\
\hline $\begin{array}{l}\text { Swath } \\
\text { Width } \\
\text { (ground } \\
\text { range) }\end{array}$ & $100 \mathrm{~km}$ & $30 \mathrm{~km}$ & $\begin{array}{l}10 \mathrm{~km} \\
\text { azimuth } \mathrm{x} \\
10 \mathrm{~km} \\
\text { ground }\end{array}$ & $\begin{array}{l}5 \mathrm{~km} \text { azimuth } \\
\mathrm{x} \\
10 \mathrm{~km} \text { ground }\end{array}$ \\
\hline $\begin{array}{c}\text { Incidence } \\
\text { angle }\end{array}$ & $20^{\circ}-45^{\circ}$ & $20^{\circ}-45^{\circ}$ & $20^{\circ}-55^{\circ}$ & $20^{\circ}-55^{\circ}$ \\
\hline $\begin{array}{c}\text { Azimuth } \\
\text { Res. }\end{array}$ & $16 \mathrm{~m}$ & $3 \mathrm{~m}$ & $2 \mathrm{~m}$ & $1 \mathrm{~m}$ \\
\hline $\begin{array}{c}\text { Ground } \\
\text { Range Res. }\end{array}$ & $1.7 \mathrm{~m}-3.5 \mathrm{~m}$ & $1.7 \mathrm{~m}-3.5 \mathrm{~m}$ & $1.5 \mathrm{~m}-3.5 \mathrm{~m}$ & $1.5 \mathrm{~m}-3.5 \mathrm{~m}$ \\
\hline
\end{tabular}

In June 2007, the TerraSAR-X (TSX) satellite reached its orbit, and since January 2008, data and products have been provided operationally to scientists (http://sss.terrasar-x.dlr.de/). TSX has a sun-synchronous near-polar dusk-dawn orbit with a mean altitude of $514 \mathrm{~km}$. It can be operated in four different modes [10], i.e., ScanSAR, StripMap, Spotlight, and highresolution (HR) Spotlight. Technical details of the different modes are summarized in Table I.

Because of its flexible swath coverage and HR as well as the interferometric and polarimetric abilities, various oceanic and atmospheric applications can be investigated using TSX data, for example, the preliminary studies of ocean surface wind, coast lines, and surface waves as described in [11].

As a unique sensor to image sea surface in two dimensions independent of weather and sunlight conditions, airborne or spaceborne SARs are suitable for investigating the spatial variations of surface waves, particularly in near-shore regions where local bathymetry, surface wind, and surface currents have active interactions with oceanic gravity waves. SAR data have been used to study the ocean wave refraction mechanisms in coastal regions caused by, e.g., bottom topography [12], ocean currents [13], [14], and ice edges [15], [16].

In this paper, Terceira island is chosen as the area of interest for observation of coastal waves by making use of TSX images acquired in different modes. Terceira island is located in the Azores archipelago between latitudes $37^{\circ}-40^{\circ} \mathrm{N}$ and longitudes $25^{\circ}-31^{\circ} \mathrm{W}$. At the north of the Azores, the dominant wave direction is between north and northwest, as generated by highlatitude storms in the North Atlantic. Distributions of these waves change locally in shoaling, refraction, and diffraction processes because of the quickly varying bathymetry at a short distance from the coast line.

The volcanic island Terceira has an elliptical form approximately $29 \mathrm{~km}$ in the $\mathrm{E}-\mathrm{W}$ direction and $18 \mathrm{~km}$ in the $\mathrm{S}-\mathrm{N}$ direction as shown in Fig. 1. Three quick looks of TSX images 


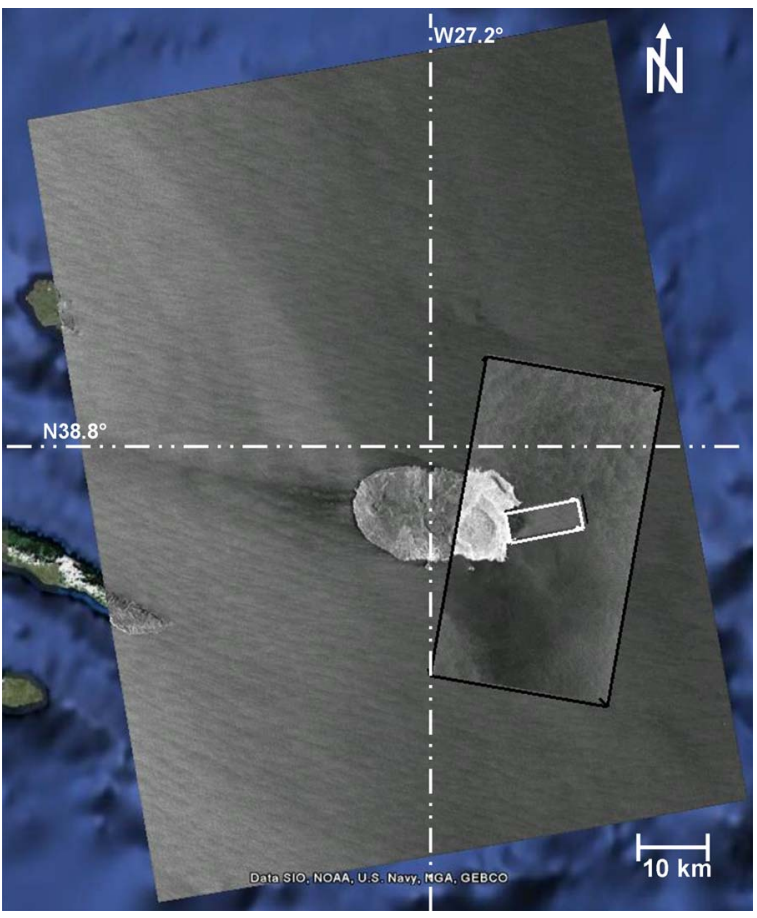

Fig. 1. Overlay of (largest one) TSX ScanSAR image acquired on March 20, 2008, (black rectangle) StripMap image acquired on January 15, 2009, and (white rectangle) Spotlight mode image acquired on March 26, 2008 over Terceira island (map in background from Google earth).

acquired over the island, which are operated, respectively, in ScanSAR, StripMap, and Spotlight modes, overlaid on top of each other, are shown as well in the figure. The ScanSAR image has the largest area coverage of 140 and $100 \mathrm{~km}$ in the azimuth and range directions, respectively, with a pixel size of $8.25 \mathrm{~m}$. Wind streaks are visible in the ScanSAR image, and surface wind blowing toward northwest is inferred by the shadow zone behind the Santa Barbara volcano $(1021 \mathrm{~m})$ at the NW end of the island. Details on the retrieval of the surface wind field from $\mathrm{X}$-band SAR (X-SAR) data are discussed in [17]. The ScanSAR image yields an overview of sea state and wind field for the entire oceanic region around Terceira island.

Inside the black rectangle, a quick look of a StripMap image acquired on January 15, 2009 in the eastern coast of Terceira island is shown. A Spotlight image represented in the white rectangle was acquired on March 26, 2008. The Spotlight image covers the area limited to $5 \mathrm{~km}$ in azimuth and $12 \mathrm{~km}$ in range over the harbor of Terceira island. Spotlight mode data are particularly suitable for investigation of near-shore processes, harbor monitoring, and comparison to in situ measurements. It can be observed that the StripMap mode scene covers the whole eastern part of the island and can be used for investigating spatial variations of wave refraction when approaching the coasts.

In this paper, wave refraction caused by the change of bottom topography at the Terceira island coast is investigated using TSX image spectra and measurements of X-band marine radar. The image spectrum extracted from the TSX Spotlight image in offshore direction shows a swell system with a peak wavelength of $181 \mathrm{~m}$ and a peak wave direction of $-34^{\circ}$ (clockwise relative to the TSX azimuth direction) generated by a high-latitude storm, whereas the one in the near-shore region shows a rotation of peak wave direction of $36^{\circ}$ and a peak wavelength decrease of $128 \mathrm{~m}$, induced by the wave refraction.

The spatial variations of wave diffraction around the entire island are investigated using a TSX image acquired in StripMap mode on January 15, 2009 and compared to the variation in bottom topography.

This paper is arranged as follows. In Section II, the SAR ocean wave mechanism is introduced briefly, in which the cutoff effect of ocean wave imaging of TSX is compared to conventional satellites. The auxiliary data, i.e., the numerical wave model WAM, measurements of X-band marine radar, and the ETOPO 1 topography model are introduced in Section III. Wave refraction and diffraction effects observed in TSX images are presented in Section IV. Basic laws describing the wave refraction in shoaling water are summarized briefly in this section. Then, the refraction effect as observed in the TSX Spotlight image with an area coverage of $5 \mathrm{~km}$ by $12 \mathrm{~km}$ is presented, and corresponding spectra derived from the TSX subscenes are compared to the measurement of marine radar WaMoS. Spatial variations of significant wave height (SWH) during the shoaling process are investigated using the laws of wave refraction and developed XWAVE empirical algorithm. Based on the TSX StripMap image with an area coverage of $30 \mathrm{~km}$ by $60 \mathrm{~km}$, the generation of a cross sea induced by the wave diffraction around Terceira island is demonstrated as well in this section. Conclusions and discussion are given in Section V.

\section{OCEAN WAVE IMAGing BY SAR}

For moderate incidence angles between $20^{\circ}$ and $60^{\circ}$, the principal scattering mechanism for SAR ocean surface imaging is Bragg scattering [18]. That is, the incident radar waves are backscattered by short capillary wave components on the ocean surface, whose wavelength $\lambda_{B}$ is related to radar wave frequency or wavelength $\lambda_{r}$ at an incidence angle $\theta$ by the following equation:

$$
\lambda_{B}=\lambda_{r} / 2 \sin \theta .
$$

For X-SAR with a wavelength $\lambda_{r}$ of $3.1 \mathrm{~cm}$, the resonant Bragg wavelength is $3.9 \mathrm{~cm}$ at an incidence angle of $\theta=23^{\circ}$, whereas a SAR operated in C-band $\left(\lambda_{r}=5.6 \mathrm{~cm}\right)$ has a longer $\lambda_{B}$ of $7.1 \mathrm{~cm}$ at the same incidence angle. This may lead to different radar signatures of the same oceanic or atmospheric phenomena as shown in simultaneous scenes acquired by multifrequency SAR, for example, the Spaceborne Imaging RadarC/X-SAR.

A two-scale model [2] is often used as the basic element to describe the SAR ocean wave imaging process, in which the short waves are responsible for the Bragg scattering mechanism. Detection of longer waves is considered to be possible through the modulation of these capillary waves by the longer ones. The model includes two modulation mechanisms, namely, tilt and hydrodynamic modulations. Orbit motion of gravity waves during SAR data acquisition time leads to a distortion of the image spectrum and cutoff in the azimuth direction [3], namely, waves shorter than a certain threshold will not be imaged by SAR. Previous research has shown that this low-pass 
filter effect is proportional to the ratio of satellite slant range $R$ to platform velocity $V$ [1]; in addition, it is supposed to be related to other parameters, such as incidence angle and scene coherence time [19], and geophysical parameters, for example, SWH [1], [19] and mean wave period $T_{z}$. As also pointed out in [20], the intrinsic scene coherence time is dependent upon surface wind speed $U_{10}$. It is believed that the SAR cutoff wavelength $\lambda_{C}$ can be determined by the following function:

$$
\lambda_{C}=F\left(\frac{R}{V}, \theta, H_{s}, T_{z}, U_{10}\right) .
$$

Different approaches, particularly some empirical relationships, have been proposed to estimate the SAR cutoff wavelength, e.g., in [1], [16], [21], and [22]. These estimations are based on the spaceborne SAR, e.g., SEASAT SAR, ERS SAR, and ENVISAT ASAR, which are operated in a higher altitude orbit and therefore have a higher value for $R / V$ of $115-120 \mathrm{~s}$. The orbit of TSX is lower, with a mean altitude of $514.8 \mathrm{~km}$, which leads to a lower $R / V$ ranging from 72 to $78 \mathrm{~s}$ corresponding to the incidence angles of $20^{\circ}-30^{\circ}$. Given the same assumptions, the imaging effects of SAR for ocean wave are significantly reduced in TSX data compared with the conventional SARs, based on some previous investigations.

\section{Auxiliary Data Description}

\section{A. WaMoS Marine Radar}

In this paper, local sea state measurements are derived from the second-generation marine radar WaMoS II, which is an operational wave monitoring system to survey the sea surface wave field in time and 2-D space. The system consists of conventional marine radar, an $\mathrm{A} / \mathrm{D}$ converter to digitize the analog radar echo signal, and a standard PC to store and process the data in real time. It is used onboard ships, oil platforms, and on shore to determine 2-D wave spectra and integrated sea state parameters such as wave peak, propagation direction, and SWH. The technique as presented in [23]-[25] has been used operationally in many locations.

The WaMoS II located on Terceira island was installed in Praia da Vitória Bay $\left(38.7^{\circ} \mathrm{N}, 27.0^{\circ} \mathrm{W}\right)$ with a scanning radius of $2.2 \mathrm{~km}$. The black dash line demonstrates the coverage of WaMoS marine radar over the port superimposed on the subscene of the StripMap mode image shown in Fig. 2.

WaMoS provides a local sea state measurement, whereas the numerical wave model gives an estimation of sea state over a large spatial scale. To verify ocean wave characteristics observed in the TSX image, the numerical wave model WAM is used to provide synergetic observations.

\section{B. Numerical Wave Model WAM}

The numerical wave model provided by the German Weather Service (DWD) is the third-generation WAM (cycle 4 [26]). The model is expressed in terms of an action balance equation

$$
\frac{\partial E}{\partial t}+C_{g}\left(\frac{\partial E}{\partial x}+\frac{\partial E}{\partial k}\right)=S=S_{\mathrm{in}}+S_{\mathrm{nl}}+S_{\mathrm{ds}}
$$

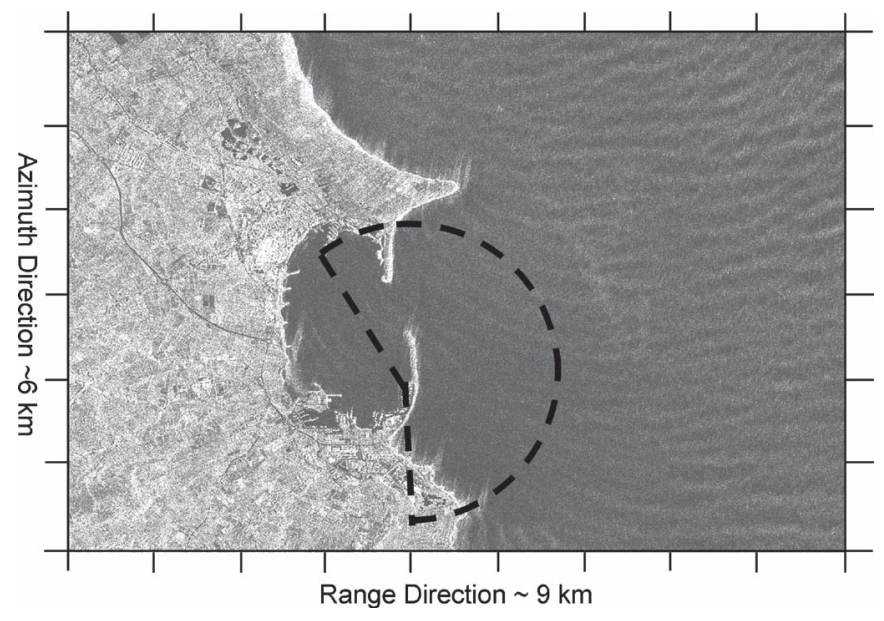

Fig. 2. Demonstration of the location and scanning coverage of WaMoS marine radar at the port of Terceira island (dash line superimposed on subscene with coverage size about $6 \mathrm{~km}$ by $9 \mathrm{~km}$ of TSX StripMap image shown in Fig. 1).

where $E=E(k, x, t)$ is the action density spectrum depending on wavenumber $k$, time $t$, and locations of $x . C_{g}$ is the deepwater group velocity. $S$ is the source function, consisting of three terms: $S_{\text {in }}$ is the energy input by wind, $S_{\mathrm{nl}}$ is the nonlinear energy transfer by wave-wave interactions, and $S_{\mathrm{ds}}$ is dissipation.

This form of equation is valid for deep water without considering refraction and significant currents. In this paper, the DWD forecast global sea wave model (GSM) is provided with a spatial resolution of $0.75^{\circ}$ and temporal resolution of $3 \mathrm{~h}$. It is used to compare to the TSX observation.

\section{Topography Data Set}

Bathymetry data used in this paper for investigating coastal wave processes are extracted from the National Geophysical Data Center ETOPO1 global relief model [27] in grid points. The spatial resolution of ETOPO1 model is 1 arc-minute.

\section{NeAR-Shore WaVE Refraction-DifFraction OBSERVED IN TSX IMAGES}

In this section, we analyze wave refraction and diffraction observed in TSX Spotlight and StripMap images, particularly for the spatial variations of wave patterns derived from different data sources, i.e., TSX imagery, WaMoS marine radar, and the wave model.

\section{A. Wave Refraction}

Propagation of ocean surface waves is described by the dispersion relationship, which relates angular frequency $\omega$ to wavenumber $k$ and water depth $h$. If the surface current $U=$ $(u, v)$ can be neglected

$$
\omega=\sqrt{g k \tanh (k h)}
$$

where $g$ is the acceleration of gravity and $\tanh (x)$ denotes the hyperbolic tangent. 


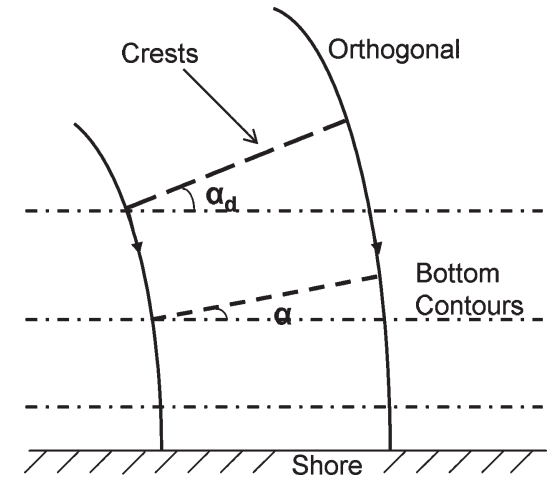

Fig. 3. Sketch of wave refraction caused by bottom topography.

In deep water, when $k h \rightarrow \infty$, the hyperbolic tangent $\tanh (k h)$ becomes approximately one, and (4) reduces to $\omega=$ $\sqrt{g k}$.

When a harmonic wave propagates over seabed topography, it begins to change as it "feels" the bottom. Because the wave period remains constant, therefore, via dispersion relationship (4), its wavelength becomes progressively shorter, and the phase speed $c$ correspondingly decreases

$$
c=\sqrt{\frac{g}{k} \tanh (k h)} .
$$

This near-shore process of surface gravity waves is called wave shoaling.

Provided that the harmonic wave approaches a straight coast at an angle $\alpha_{d}$, a part of the wave in deep water moves more rapidly than it does in shallow water (as shown in (5) for phase speed). The effect causes the wave to turn parallel to the bottom contours. This phenomenon is called wave refraction as shown in Fig. 3.

During the wave refraction process, the change of wave height becomes rather complex. Wave height $H$ in shoaling water is quantified by using [28]

$$
H=H_{d} D K
$$

in which $H_{d}$ is the SWH in deep water. $D$ is called shoaling coefficient given by

$$
D=\left(\frac{k}{k_{d}}\right)^{1 / 2}\left(1+\frac{2 k h}{\sinh (2 k h)}\right)^{-1 / 2}
$$

and $K$ is used to refer to the refraction coefficient as determined by

$$
K=\left(\frac{\cos \left(\alpha_{d}\right)}{\cos (\alpha)}\right)^{1 / 2}
$$

By using Snell's law, $\alpha$ in (8) is expressed by

$$
\alpha=\sin ^{-1}\left(\frac{k_{d}}{k} \sin \left(\alpha_{d}\right)\right) .
$$

It can be observed that the shoaling effect of $D$, which is only relative to the water depth alone, acts first to decrease the wave height as the waves shoal, and then, when the depth becomes rather shallow, reaching some threshold (e.g., ratio of shallow water depth to wavelength in deep water lower than 0.056 proposed in [28]), the wave height increases again. The coefficient $K$ is taken relative to the approaching angle $\alpha_{d}$ of the waves in deep water. Therefore, change of wave height during the wave refraction process is effected by both factors. Wave height in coastal refraction process is estimated by making use of the TSX Spotlight data based on the wave refraction laws.

\section{B. Observation of Wave Refraction and Diffraction by TSX}

In this section, TSX observations of wave refraction and diffraction are demonstrated. A TSX Spotlight image acquired on March 26, 2008 is used first in analyzing the wave refraction.

In Fig. 4(a), SWH of the total sea and the peak wavelength and wave direction of swell and windsea components derived from the DWD GSM model on March 26, 2008, at 18:00 UTC, are shown. The model results are approximately $1.5 \mathrm{~h}$ earlier than the acquisition of the TSX Spotlight data.

The gray areas on the map indicate the position of the Azores archipelago. SWH in this region is in the range of $2.0-2.5 \mathrm{~m}$ as given by the wave model. One storm with SWH higher than $6 \mathrm{~m}$, located approximately $1000 \mathrm{~km}$ northwest, generates long swell propagating toward southeast. Swell (marked with a dash-dot line) with a wavelength of around $180 \mathrm{~m}$ is observed in the local region of Terceira island as shown in Fig. 4(b), where the windsea becomes as low as $0.5 \mathrm{~m}$. The sea state of Terceira island at this time is dominated by a swell system.

In Fig. 5, the TSX Spotlight image acquired over the Terceira eastern coast in an ascending orbit is superimposed with topography data derived from the ETOPO1 model. The coverage of the TSX Spotlight image is approximately $5 \mathrm{~km}$ in azimuth and $12 \mathrm{~km}$ in range with resolutions of 2.8 and $3.5 \mathrm{~m}$, respectively, at a pixel size of $1.25 \mathrm{~m}$. Five subscenes, namely, A, B, C, $\mathrm{D}$, and $\mathrm{E}$, with 1024 by 1024 pixels covering an area of around $1 \mathrm{~km}$ by $1 \mathrm{~km}$ shown on the TSX image are used for demonstration of the spectral analysis. A standard fast Fourier transform method is used for the estimation of image spectrum. Between B and D, the TSX image is divided into four rows and six columns, with the same size of 1024 by 1024 pixels for every subscene. The image spectra for the subscenes are shown in Fig. 6 to follow the spatial variations of gravity waves in the near-shore region. For the plots in Fig. 6, the spectral density value is scaled relatively to the reference maximum.

The spatial resolution of the DWD GSM wave model is $0.75^{\circ} \times 0.75^{\circ}$, and the estimation for the integrated wave parameters to the nearest grid in the TSX image is located at $39^{\circ} \mathrm{N}, 27^{\circ} \mathrm{W}$, which is approximately $30 \mathrm{~km}$ away from the TSX image subscene D. SWH, peak wavelength, and direction as estimated by the DWD GSM model is $2.1 \mathrm{~m}, 176 \mathrm{~m}$, and $-45^{\circ}$ (clockwise to the TSX azimuth direction), respectively. The same peak resolved by the DWD model is observed as well in the TSX image, as shown in its image spectra D in Fig. 6, denoted by P1. Peak wavelength and direction derived from the TSX image spectra of D is $181 \mathrm{~m}$ and $-34^{\circ}$, respectively, which is comparable to the numerical wave model results.

From top to bottom in the first column of Fig. 6, the peak wave direction and wavelength show a significant change as 


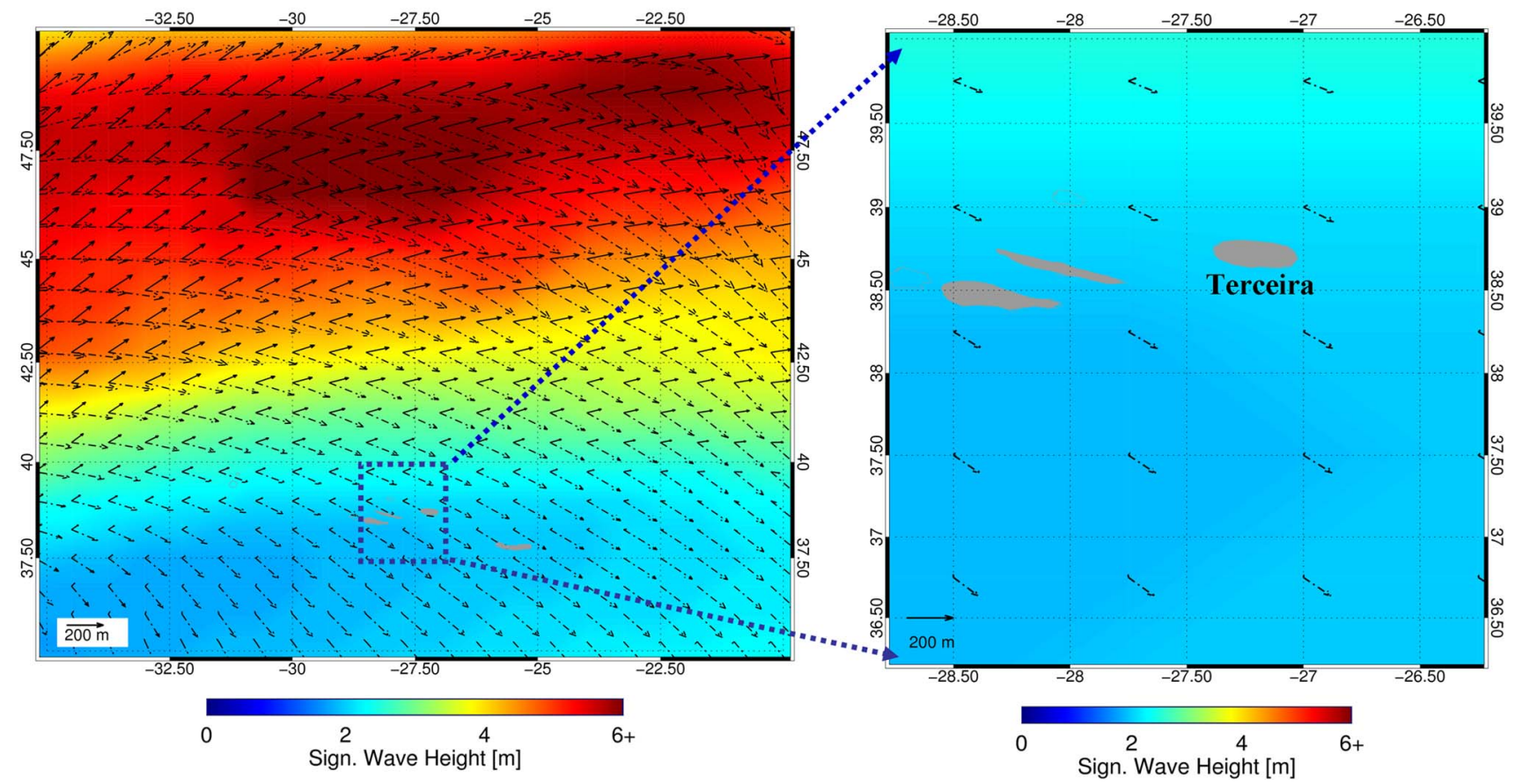

Fig. 4. (Background) SWH and the peak wavelength and direction for (solid line) windsea and (dash-dot line) swell derived from the DWD GSM wave model for (a) large coverage and (b) local region of Azores islands on March 26, 2008 at 18:00 UTC.

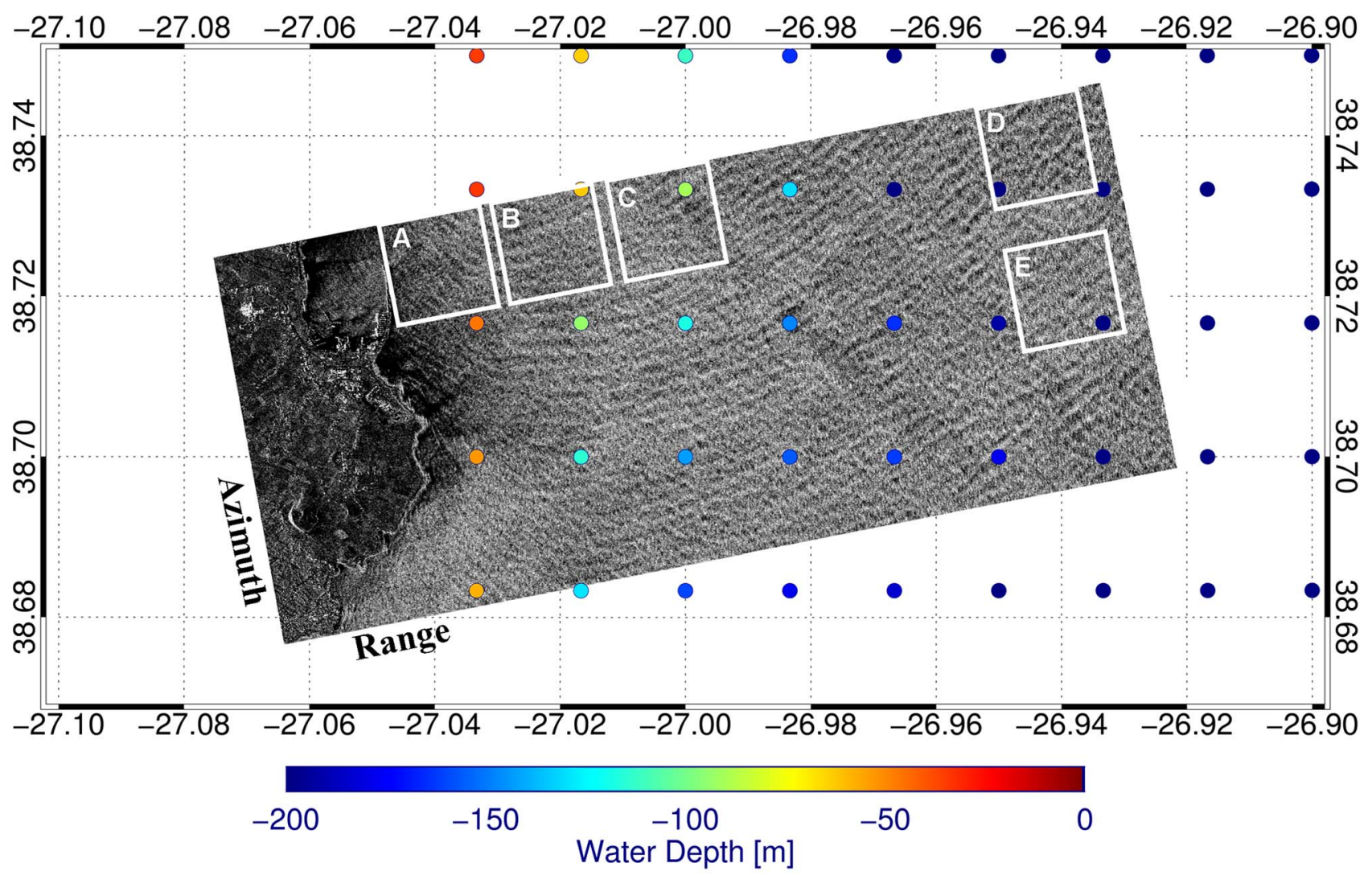

Fig. 5. TSX Spotlight image acquired over Terceira island on March 26, 2008, at 19:32 UTC. Five subscenes marked as A, B, C, D, and E are used for spectral analysis. Bottom topography given by the ETOPO 1 model is superimposed on the TSX image in grid points.

observed in the spectra. Spectrum D agrees with model results in offshore with a peak wave direction of $-34^{\circ}$, whereas along the distance toward the inshore, the peak undergoes a clockwise rotation as observed in the spectrum $B$ for a peak wave direction of $14^{\circ}$. Because of the coarse spatial resolution of the numerical wave model, it cannot describe the coastal processes in detail. 


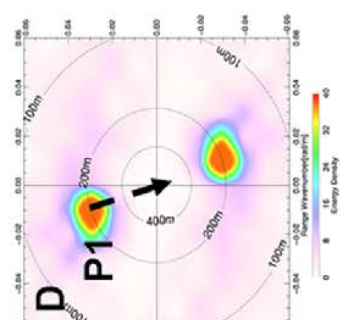

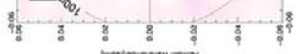
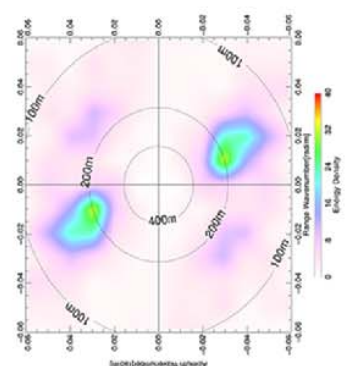

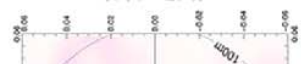
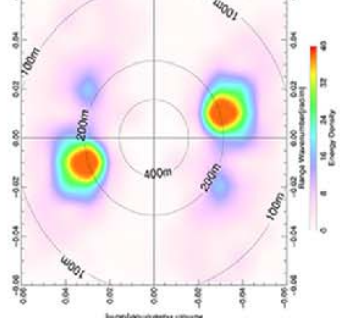

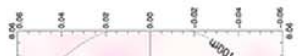
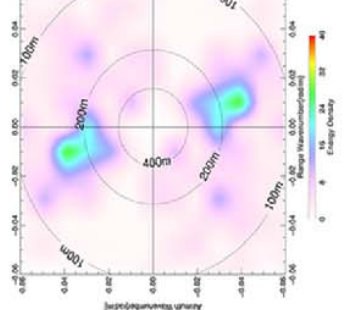

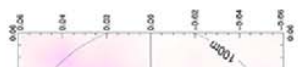
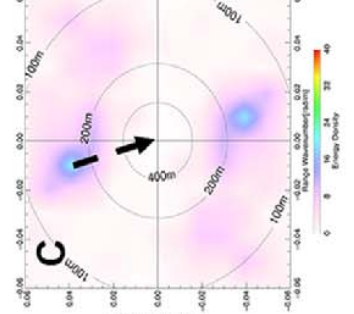

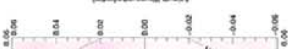

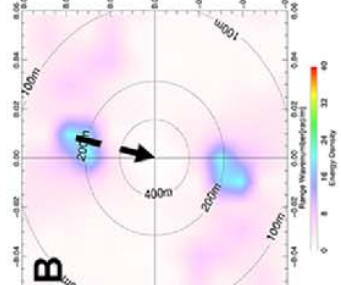

$\boldsymbol{m}_{0,}$
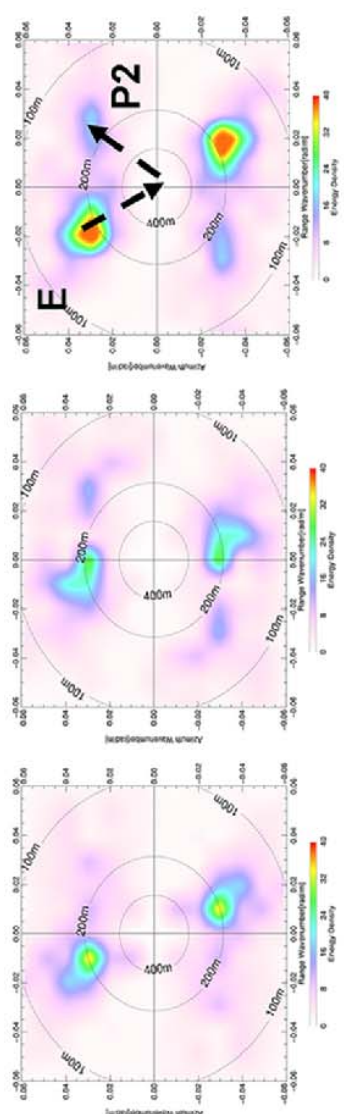

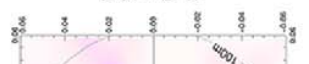
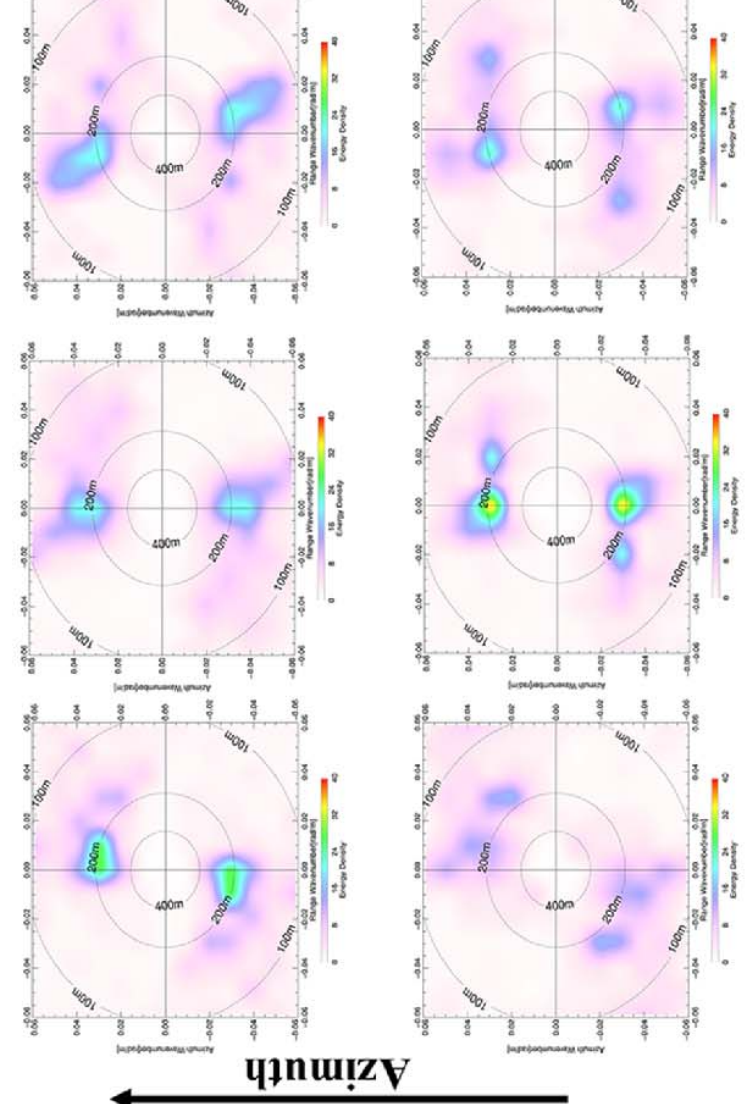
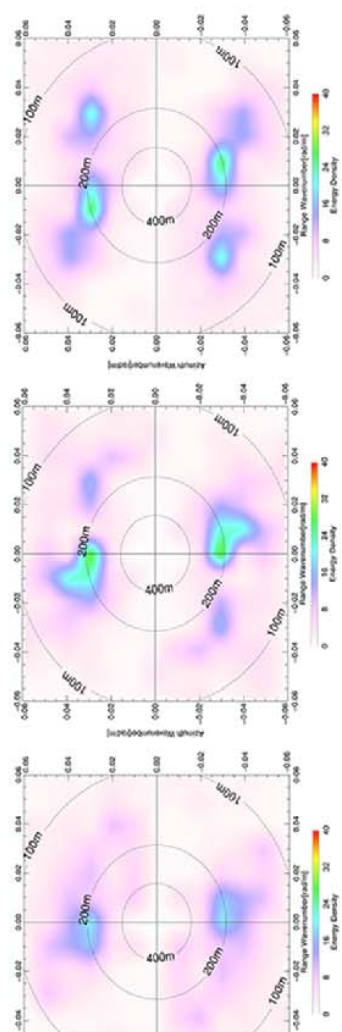

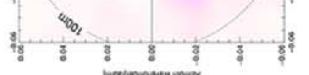

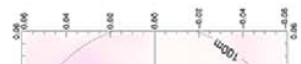
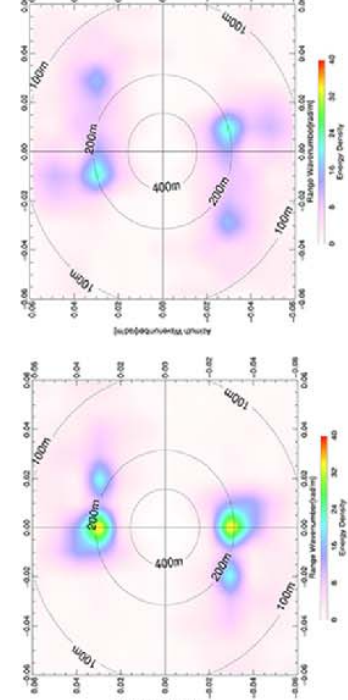

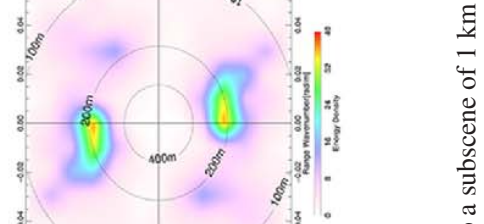

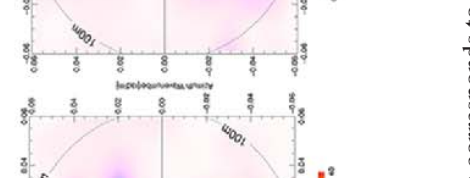

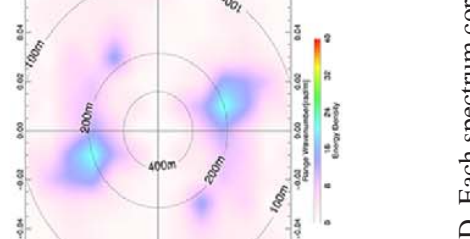

$$
\text { Din }
$$

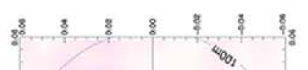

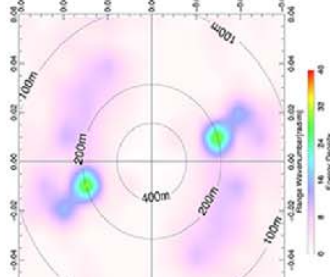

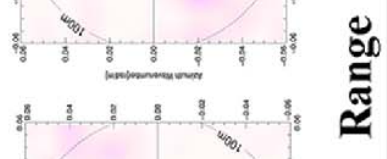
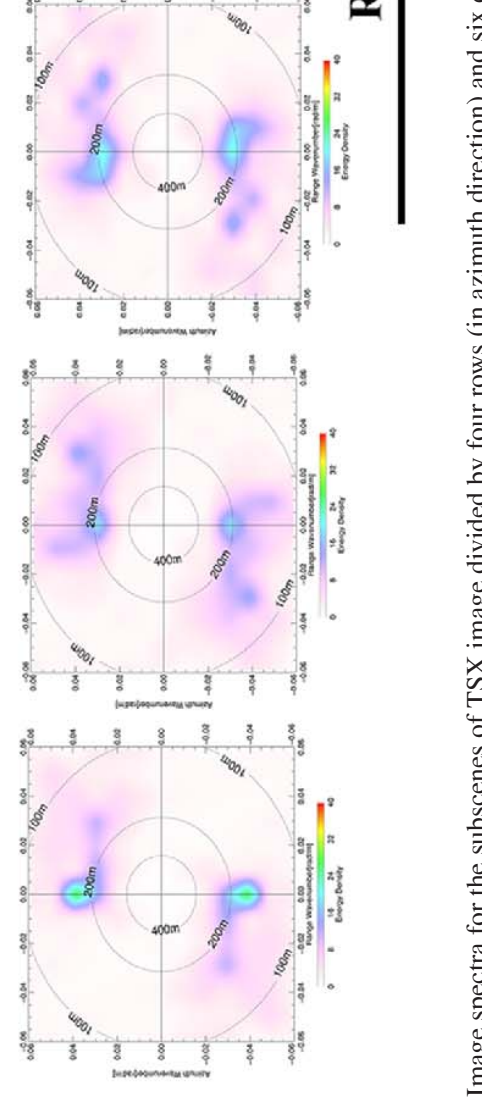

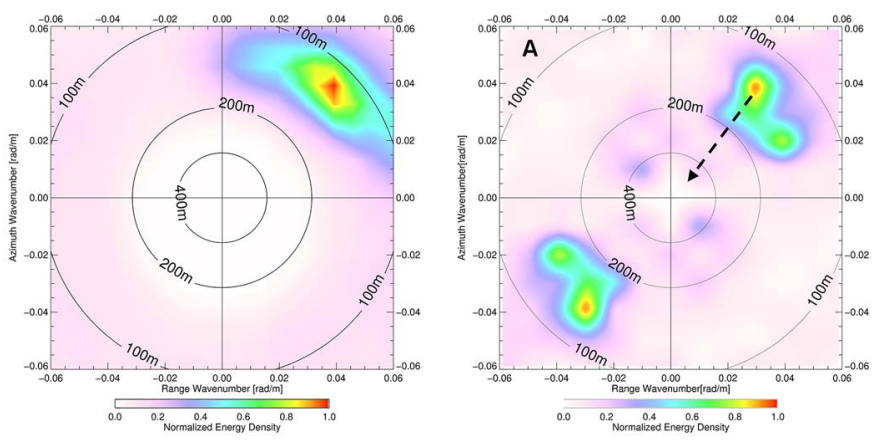

Fig. 7. (Right) TSX image spectra corresponding to the subscene A shown in Fig. 5 with normalized energy density scale and (left) the spectrum estimated by the marine radar with normalized energy density.

TABLE II

Peak WaVe Direction and Length of P1 Derived From tSX Image SPeCtra of Subscenes A, B, C, AND D Shown in Figs. 6 And 7

\begin{tabular}{ccc}
\hline \hline $\begin{array}{c}\text { No. of subscene of } \\
\text { TSX image }\end{array}$ & Peak wavelength $(\mathrm{m})$ & $\begin{array}{c}\text { Peak wave direction } \\
\text { (clockwise relative to } \\
\text { azimuth direction) }\end{array}$ \\
\hline A & 128 & $36^{\circ}$ \\
B & 155 & $14^{\circ}$ \\
C & 155 & $-14^{\circ}$ \\
D & 181 & $-34^{\circ}$ \\
\hline \hline
\end{tabular}

TABLE III

Parameters Determined From the TSX IMAge Spectra Used FOR ESTIMATING SWH FOR SUbSCENES OF A, B, AND C

\begin{tabular}{cccc}
\hline \hline $\begin{array}{c}\text { No. of } \\
\text { subscene in } \\
\text { TSX image }\end{array}$ & $\begin{array}{c}\text { Angle between wave } \\
\text { and bottom topography }\end{array}$ & $\begin{array}{c}\text { Peak } \\
\text { wavelength } \lambda \\
(\mathrm{m})\end{array}$ & $\begin{array}{c}\text { Water depth } \\
h(\mathrm{~m})\end{array}$ \\
\hline A & $25^{\circ}$ & 128 & 33 \\
B & $3^{\circ}$ & 155 & 62 \\
C & $25^{\circ}$ & 155 & 90 \\
\hline \hline
\end{tabular}

The WaMoS marine radar located in the bay of Terceira has a similar scanning coverage as TSX subscene A. The TSX simultaneous measurement of the WaMoS marine radar was acquired at 19:30 UTC. The 2-D spectrum retrieved from the intensity backscatter of WaMoS is shown in Fig. 7 (left). This spectrum is rotated to show the same coordinate direction with the TSX image heading direction, i.e., $348.6^{\circ}$ clockwise relative to north. Peak wave direction and wavelength estimated by the marine radar are $50^{\circ}$ (clockwise relative to the TSX azimuth direction) and $117 \mathrm{~m}$, respectively. Both parameters derived from the nearest TSX subscene image spectrum A are $36^{\circ}$ and $128 \mathrm{~m}$, respectively. The slight difference may be caused by the larger scanning region of the marine radar than the coverage of subscene A over the inhomogeneous sea surface near the coast.

By comparing to the results of numerical wave model and marine radar, it can be observed that the peak wave direction has a rotation of approximately $70^{\circ}$ from the TSX image spectra of subscenes D, C, B, and A along the shoreward direction, as summarized in Table II, for the peak $\mathbf{P 1}$.

Examining the water-depth estimation given by the ETOPO 1 model shown in Fig. 5, from D to A, bathymetry changes significantly, particularly from deeper than $200 \mathrm{~m}$ to shallower than $30 \mathrm{~m}$. When the swell propagates toward Terceira island, because of the change of underwater topography, wave refraction occurs in the near-shore region. As the approaching swell
TABLE IV

SWH Estimated From TSX Data IN Subscenes A, B, AND C USING WAVE REFRACTION LAWS AND EMPIRICAL ALgORITHM XWAVE

\begin{tabular}{|c|c|c|c|}
\hline $\begin{array}{c}\text { No. of } \\
\text { subscene } \\
\text { in TSX } \\
\text { image }\end{array}$ & $\begin{array}{l}\text { SWH }(\mathrm{m}) \text { by refraction } \\
\text { law using DWD model } \\
\text { results as the } \\
\text { measurements in deep } \\
\text { water }\end{array}$ & $\begin{array}{l}\text { SWH (m) by } \\
\text { refraction law using } \\
\text { XWAVE results as } \\
\text { the measurements in } \\
\text { deep water }\end{array}$ & $\begin{array}{l}\text { SWH (m) by } \\
\text { XWAVE } \\
\text { empirical } \\
\text { algorithm }\end{array}$ \\
\hline A & 1.6 & 1.7 & 1.9 \\
\hline B & 1.7 & 1.9 & 2.2 \\
\hline $\mathrm{C}$ & 1.8 & 2.0 & 2.3 \\
\hline
\end{tabular}
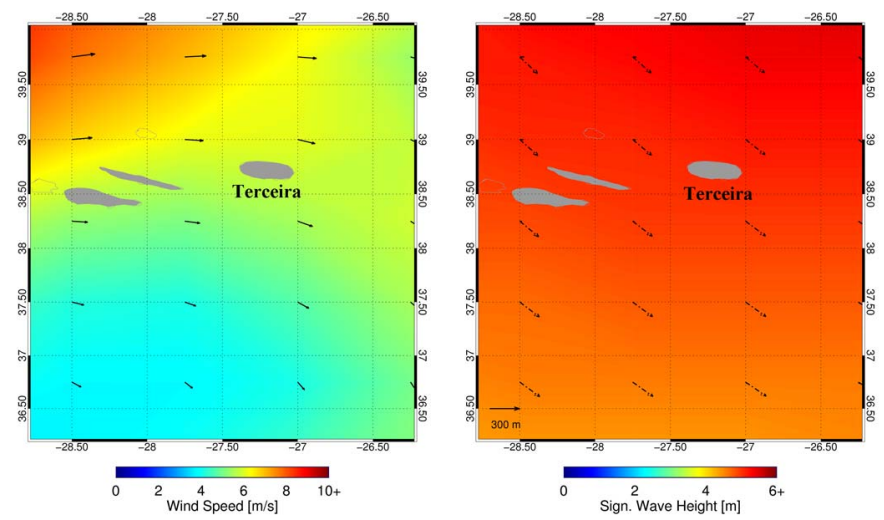

Fig. 8. (a) Wind field and (b) SWH (background) with peak wave direction of swell and windsea derived from the DWD GSM wave model around Terceira island on January 15, 2009 at 9:00 UTC.
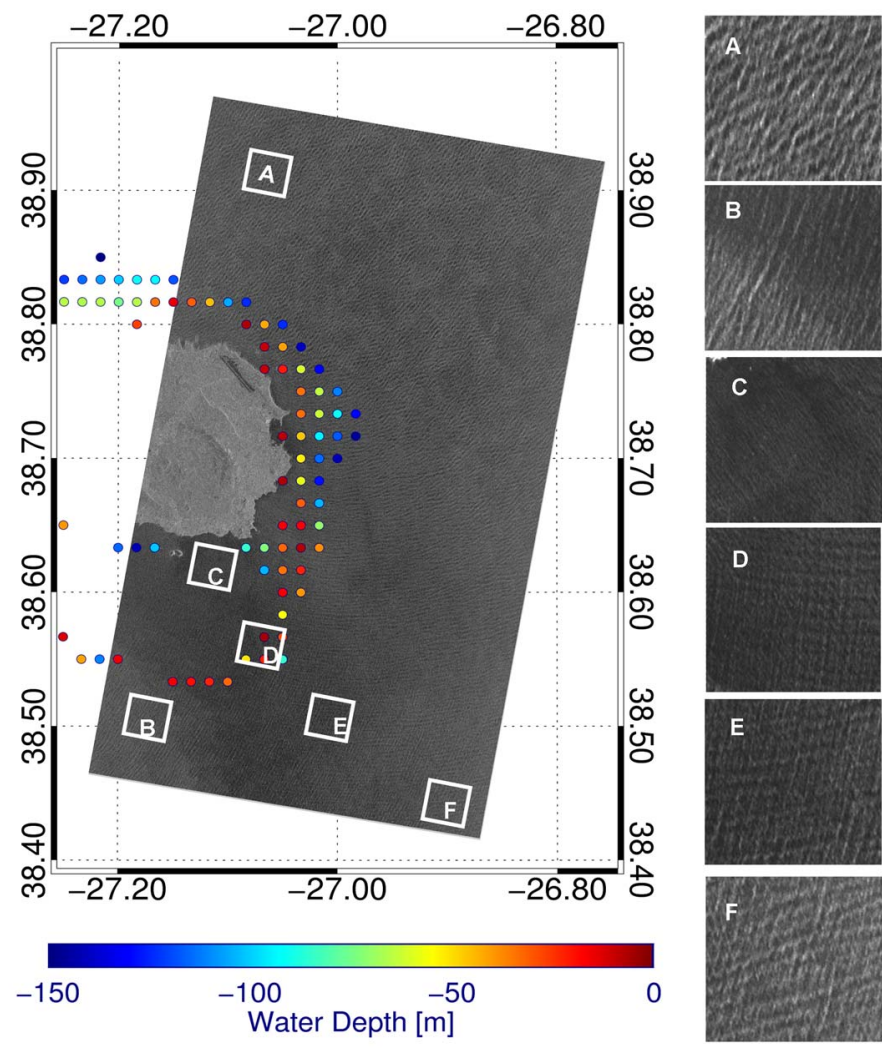

D

Fig. 9. TSX StripMap mode image (around $30 \mathrm{~km}$ by $60 \mathrm{~km}$ ) acquired over Terceira island on January 15, 2009 at 7:55 UTC. Six subscenes marked as A, $\mathrm{B}, \mathrm{C}, \mathrm{D}, \mathrm{E}$, and $\mathrm{F}$ are used for spectral analysis. Bottom topography derived from the ETOPO 1 model is superimposed on the TSX image in grid points. The right panel shows the enlarged subscenes. 
has an angle with the bottom topography contours, wave crests bend parallel to the coast as observed by the rotation of peaks in the TSX image spectra from D to A. Furthermore, wave refraction also leads to the bending of crest parallel to the eastern coast of Terceira island. It can be observed in the second column of Fig. 6 how the peak rotates from $-14^{\circ}$ of $\mathrm{C}$ to nearly $0^{\circ}$, traveling in the azimuth direction.

By using TSX data, the spatial variability of near-shore wave behavior is resolved well. On the other hand, the spectral information can be used to deduce situation on underwater topography. It should be noted that a limitation of using SAR intensity image spectra is $180^{\circ}$ ambiguity for the ocean wave propagation direction. If complex data are available, this can be resolved using a cross-spectral approach [6], [7].

As introduced in Section IV-A, when wave refraction occurs, besides the change of wavelength and wave direction, the transformation of wave height occurs as well. Here, we first estimate wave height from the TSX image based on the wave refraction law.

The DWD GSM model gives, in deep water, an SWH $H_{d}$ of $2.1 \mathrm{~m}$, a peak wavelength $\lambda_{d}$ of $176 \mathrm{~m}$, and an angle between wave propagation and bottom topography contour $\alpha_{d}$ of $54^{\circ}$ (assuming that the water-depth contour is parallel to the north-south direction), which are used as the reference measurements in deep water. Parameters determined from the TSX image spectra used for estimating SWH for subscenes of $\mathrm{A}, \mathrm{B}$, and $\mathrm{C}$ are listed in Table III.

Following (7), the shoaling effect caused by water depth is estimated for the site of subscene A. Water depth $h$ for site A is $33 \mathrm{~m}$. Then, the shoaling coefficient $D_{A}$ (with the subscript used to denote subscene A) is calculated to be 0.928 , and via (8), the refraction coefficient $K_{A}$ is estimated to be 0.805 . Thus, one can estimate the SWH in the TSX subscene A to be $1.6 \mathrm{~m}$ through (6). Implementing the same method for subscenes B and $\mathrm{C}$, the SWH estimated from the TSX image is given in the second column of Table IV. For the calculations, $H_{d}, \lambda_{d}$, and $\alpha_{d}$ are derived from the DWD model results of $2.1 \mathrm{~m}, 176 \mathrm{~m}$, and $54^{\circ}$.

An empirical algorithm XWAVE was developed to estimate an integral wave parameter, i.e., SWH, from TSX data. Expression of the geophysical model function of the XWAVE algorithm is given in the following equation:

$$
S W H=a * 4.0 * \sqrt{E *(1.0+\cos (\alpha))}+b .
$$

In the equation, $E$ is the total energy calculated from the TSX image wavenumber spectrum $\mathbf{F}(\vec{k})$ via

$$
E=\int \mathrm{F}(\vec{k}) d \vec{k}
$$

and $\alpha\left(\leq 90^{\circ}\right)$ represents the angle between the peak wave direction (with $180^{\circ}$ ambiguity) and the SAR flight direction and is also determined from the image spectra. Two coefficients $a$ and $b$ are tuned by using hindcast results of the DWD wave model. In situ buoy measurements will be used as the ground truth for further tuning.

In this case, SWH estimated by XWAVE for subscene D is $2.4 \mathrm{~m}$, which is slightly higher than the DWD GSM model result of $2.1 \mathrm{~m}$. Choosing the result for SWH from D estimated by using the XWAVE algorithm as the initial value for deep water, the SWHs for subscenes of A, B, and C are determined by using the wave refraction law. Results are given in the second column of Table IV. The SWH measured by the WaMoS marine radar is $1.2 \mathrm{~m}$, which is lower than other estimations from the model and TSX data.

SWHs for the three subscenes calculated directly by using the XWAVE algorithm are given as well in the third column in Table IV. It shows a slightly higher estimation than using the refraction law. Further tuning for the coefficients in (10) is under investigation, including cases of different sea state.

In this case study, the GSM wave model provides regional view of the incoming swell system, and the TSX data, as well as its image spectra, show good agreement of the swell system in the offshore region when compared to the model. Interaction of surface gravity waves and bottom topography are depicted by the TSX image, which cannot be resolved in the model because of limitation of spatial resolution. The WaMoS provides simultaneous measurement for a small scanning area near the coast. This is particularly suitable for harbor monitoring. The TSX data are an effective tool to derive the spatial variations of wave behavior and processes (e.g., refraction, shoaling, and breaking) in the near-shore region.

In the SAR spectrum of E shown in Fig. 6, another peak denoted by $\mathbf{P} 2$ can be observed at an angle of around $45^{\circ}$ to peak P1 and thus generates a cross sea [29]. Because of the limited spatial coverage of the TSX Spotlight image used, we cannot tell where the second wave component is from. Therefore, in addition, a large-coverage StripMap image is used to examine the generation of cross sea. In the following, the StripMap data acquired on January 15, 2009, as marked by the black rectangle in Fig. 1, are used for the analysis.

Sea state situation derived from the DWD GSM model on January 15, 2009, at 9:00 UTC, is chosen as the synergetic observation together with the StripMap mode image. The wind field of the GSM model is shown in Fig. 8(a). The nearest model grid point to the TSX image is located at $39^{\circ} \mathrm{N}, 27^{\circ} \mathrm{W}$, where the wind speed is $6.0 \mathrm{~m} / \mathrm{s}$ from northeast. $\mathrm{SWH}$, together with peak wave direction for windsea and swell, is shown in Fig. 8 (b). At $39^{\circ} \mathrm{N} / 27^{\circ} \mathrm{W}$, the swell and windsea wave heights are 5.2 and 0.1 , respectively, and the swell peak wavelength is $285 \mathrm{~m}$ in the direction toward southeast. Therefore, the sea state around the Azores is thus dominated by strong swell during the acquisition time of the TSX StripMap image.

Fig. 9 shows the TSX StripMap image acquired over the eastern Terceira island on January 15, 2009 at 7:55 UTC. Ground coverage of the StripMap image is $30 \mathrm{~km}$ in range and $60 \mathrm{~km}$ in azimuth with a spatial resolution of $3.0 \mathrm{~m}$ in both directions. Like the Spotlight image shown in Fig. 5, the bottom topography derived from the ETOPO1 model is superimposed as well on the StripMap TSX image. Only gridpoint measurements of water depth shallower than $150 \mathrm{~m}$ are superimposed on the TSX image. One can observe that, in the offshore region approximately $18 \mathrm{~km}$ south of Terceira island, water depth is deeper than $150 \mathrm{~m}$, which is different from the northern coast. In the northern coastal region, as previously analyzed, long swell crests bend parallel to the coast line caused by refraction, whereas in the southern coast, the crest wave 

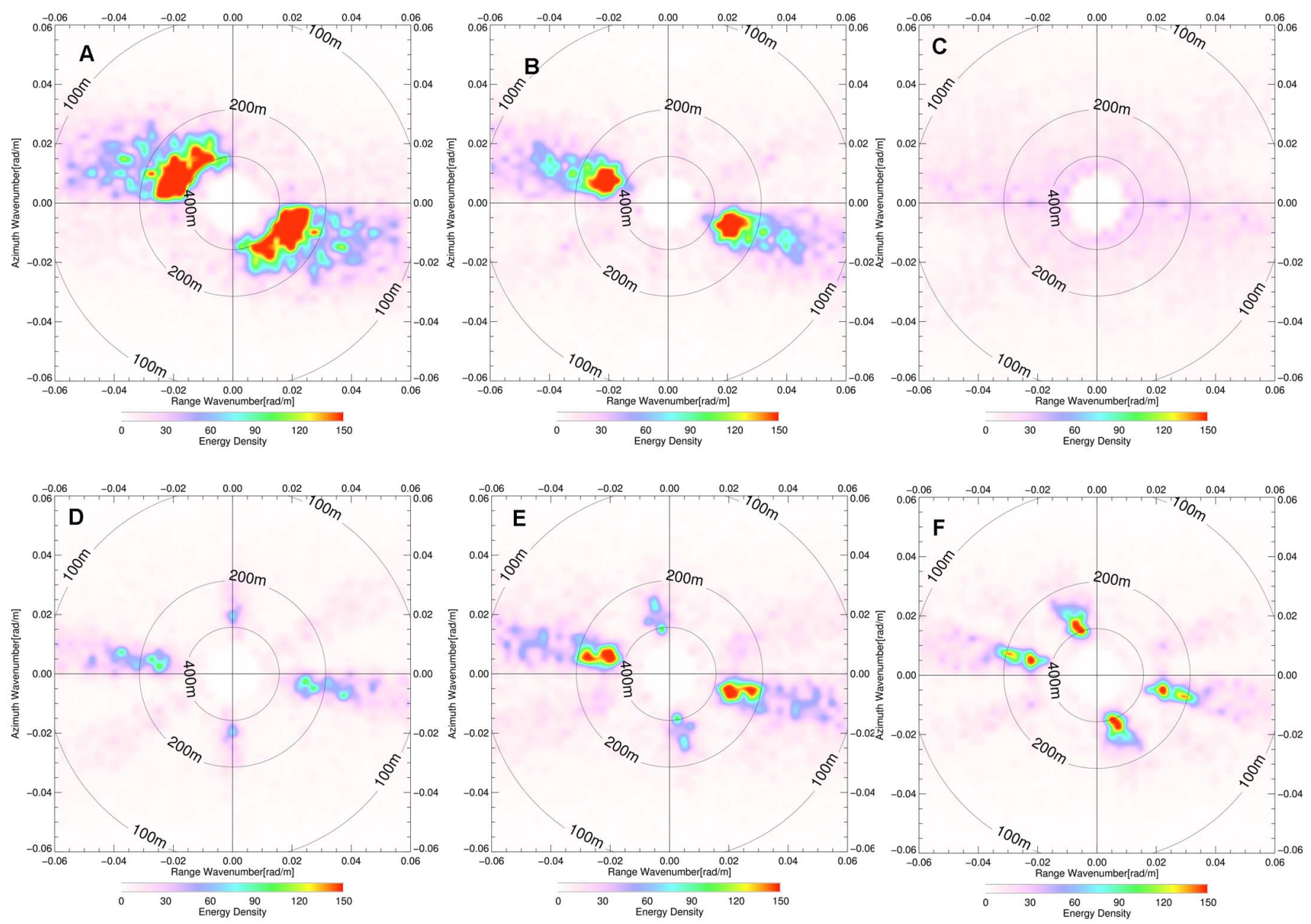

Fig. 10. SAR image spectra derived from the subscenes of A, B, C, D, E, and F as represented by the white squares in Fig. 9. Spectral intensity value is scaled with respect to spectrum A.

direction does not change significantly, which is mainly due to the steep gradient in the bottom topography, resulting in less refraction of the long waves.

Six subscenes marked by white squares on the StripMap image are used for analyzing the spatial variability of the surface waves induced by interactions with the bottom. The corresponding image spectra of the subscenes are shown in Fig. 9. Subscenes A and B are chosen in the north and south around $30 \mathrm{~km}$ away from the island in deep water (with water depth deeper than $200 \mathrm{~m}$ ). These areas are used to determine the sea state of the wave trains approaching the island.

In the image spectra of $\mathrm{A}$ and $\mathrm{B}$, one can observe that swell with a peak wavelength of around $300 \mathrm{~m}$ propagates toward the island, as comparable to the results of the DWD GSM wave model. Narrower energy peaks are found in the image spectra of B than in A. This indicates that less directional spreading of waves exists near the southern coast.

A sheltered region located at the southeastern edge of the island is quite distinct in the TSX image. When long waves are intercepted by a barrier such as the Terceira island in the present case, a shadow zone appears in the lee side of the island. Subscenes of C, D, and E are chosen in the shadow zone, and $\mathrm{F}$ is out of the region. As shown in the spectrum of Fig. 10, swell component propagating along the southern coast almost disappears in the image spectra of $\mathrm{C}$. The spectral density value for this swell component increases gradually further away from the coast, as observed in the image spectra of D and E, as well as the backscatter intensity in the TSX image subscenes.

The generation of shadow zone and penetration of wave energy into the region to the lee of the island are determined by wave refraction, diffraction, and variability in the direction of wave travel. The influence of these factors is investigated separately in [30], although they are not independent. In the present case, the water depth in the region between B and $\mathrm{C}$ changes significantly from less than $10 \mathrm{~m}$ to deeper than $200 \mathrm{~m}$, while the peak wavelength in the region B is approximately $300 \mathrm{~m}$ which is comparable to the water depth. This may lead to less wave refracting in the $\mathrm{C}$ region. Therefore, the sheltered region in the lee side of Terceira is influenced jointly by the wave diffraction and refraction.

Furthermore, with respect to $\mathrm{D}$, in addition to the wave component that propagates along the southern coast of the island, the spectra also indicate another wave component. This wave component propagates in the direction of south-north parallel to the Terceira eastern coast, where the water depth is shallower than $100 \mathrm{~m}$. Therefore, the second wave component observed in $\mathrm{D}$ is the refracted wave propagating from the north of the island. 
In the SAR image spectrum and subscene of $\mathrm{F}$, the crosssea feature becomes distinct. Nevertheless, generation of this cross sea is different from the one observed in D. In addition to the same wave component coming from the south of Terceira island, the other one is the diffracted wave from the north. Both wave refraction and diffraction can cause a change in the wave traveling direction. The former tends to be parallel to the coasts in the shallow water, whereas the wave direction is bent surrounding to the obstacle in diffraction.

\section{CONCLUSION AND Discussion}

In this paper, we have demonstrated the capability of different TSX modes to image surface gravity waves. Compared to conventional ERS SAR and ENVISAT ASAR, TSX has a lower $R / V$ value, which provides the possibility to analyze ocean wave information directly using TSX image spectra.

To demonstrate the capabilities of TSX imaging of surface gravity waves in detail, a case study of wave refractiondiffraction occurring around Terceira island is analyzed. It is performed by using the TSX Spotlight and Stripmap mode image together with other auxiliary data, i.e., numerical wave model, simultaneous measurement of X-band marine radar, and ETOPO 1 topography data.

In the northern coast of Terceira island, wave refraction is caused by the rapid change of bottom topography that bends the crests of incoming long swell parallel to the coastal line. Simultaneous measurement of marine radar WaMoS in Praia da Vitória Bay shows the near-coast peak wave directions different from the numerical wave model of DWD. By analyzing the 2-D SAR image spectra derived from the Spotlight image, how the incoming long swell wave crests bent parallel to the coast can be observed. Along the direction toward the shore, four TSX subscenes' image spectra are compared, showing that the peak wave direction is rotated from $36^{\circ}$ clockwise relative to the azimuth direction of $-33^{\circ}$, while the wavelength decreases from 181 to $128 \mathrm{~m}$ during the wave refraction process.

In the present case, variability of SWH during the refraction process is investigated through two different methods. Following the wave refraction laws, when the results of the DWD GSM model used as the initial value for deep water were taken, SWH is estimated to be $1.6 \mathrm{~m}$ near the coast, which is around $0.4 \mathrm{~m}$ higher than the measurement of WaMoS marine radar. Empirical algorithm XWAVE is developed to derive SWH directly from TSX data. Retrieved SWH in the present case for near coast is $1.9 \mathrm{~m}$, which is rather higher than the measurement from WaMoS. When taking the XWAVE result in deep water as the initial value and following the wave refraction law, the estimated SWH in near coast is $1.7 \mathrm{~m}$. The comparison results indicate that the retrieved results using the XWAVE algorithm are reasonable while needing further improvement, including the different sea state.

When considering the role of the entire Terceira island in the ocean wave variability, it can cause wave diffraction when long swell approaches. The phenomenon is analyzed by using a TSX StripMap mode scene with coverage of $30 \mathrm{~km}$ by $60 \mathrm{~km}$. Image spectra derived from the StripMap show the wave behavior before and after diffraction. Two subscenes of $3 \mathrm{~km}$ by
$3 \mathrm{~km}$ in the TSX StripMap image located in the north and south of the Terceira island show that long swell with a peak wavelength of about $300 \mathrm{~m}$ approaches the island. The shadow zone is identified in the lee side of the Terceira island. This sheltering effect is found to be influenced by wave refraction and diffraction jointly. A cross-sea feature observed behind the island is generated by refracted and diffracted waves, whereas in the seaward, it has strongly been affected by the diffracted waves surrounding the island.

As Terceira island is located at high latitude in the North Atlantic, ocean swell constantly arrives from distant storms or cyclones. Therefore, the TSX images can capture wave refraction-diffraction in this situation.

The TSX images with HR and suitable coverage size will be particularly used as a good tool to observe spatial variability of coastal ocean wave behavior. This will contribute to coastal engineering, infrastructure protection, and local numerical wave model development.

\section{ACKNOWLEDGMENT}

The authors would like to thank Dr. T. Bruns from DWD for providing the GSM wave model data and Prof. H. Graßl for the helpful comments and discussions. The authors would also like to thank the reviewers for their valuable comments on this paper. The WaMoS data are provided by OceanWaveS GmbH.

\section{REFERENCES}

[1] R. C. Beal, D. G. Tilley, and F. M. Monaldo, "Large- and small-scale spatial evolution of digitally processed ocean surface wave spectra from the SEASAT synthetic aperture radar," J. Geophys. Res., vol. 88, no. C3, pp. 1761-1778, 1983.

[2] K. Hasselmann, R. K. Raney, W. J. Plant, W. Alpers, R. A. Shuchman, D. R. Lyzenga, C. L. Rufenach, and M. J. Tucker, "Theory of synthetic aperture radar ocean imaging: A MARSEN view," J. Geophys. Res., vol. 90, no. C3, pp. 4659-4686, May 1985.

[3] W. Alpers and C. Brüning, "On the relative importance of motion-related contributions to the SAR imaging mechanism of ocean surface waves," IEEE Trans. Geosci. Remote Sens., vol. GRS-24, no. 6, pp. 873-885, Nov. 1986.

[4] K. Hasselmann and S. Hasselmann, "On the nonlinear mapping of an ocean wave spectrum into a synthetic aperture radar image spectrum," J. Geophys. Res., vol. 96, no. C6, pp. 10 713-10729, 1991.

[5] H. E. Krogstad, "A simple derivation of Hasselmann's nonlinear oceansynthetic aperture radar transforms," J. Geophys. Res., vol. 97, no. C2, pp. 2421-2425, Feb. 1992.

[6] G. Engen and H. Johnson, "SAR-ocean wave inversion using image cross spectra," IEEE Trans. Geosci. Remote Sens., vol. 33, no. 4, pp. $1047-$ 1056, Jul. 1995.

[7] S. Lehner, J. Schulz-Stellenfleth, J. B. Schättler, H. Breit, and J. Horstmann, "Wind and wave measurements using complex ERS-2 wave mode data," IEEE Trans. Geosci. Remote Sens., vol. 38, no. 5, pp. 2246 2257, Sep. 2000.

[8] J. Schulz-Stellenfleth, S. Lehner, and D. Hoja, "A parametric scheme for the retrieval of two-dimensional ocean wave spectra from synthetic aperture radar look cross spectra," J. Geophys. Res., vol. 110, no. C5, pp. C05 004.1-C05 004.17, 2005, DOI: 10.1029/2004JC002822.

[9] P. Heimbach, S. Hasselmann, and K. Hasselmann, "Statistical analysis and intercomparison with WAM model data of three years of global ERS1 SAR wave mode spectral retrievals," J. Geophys. Res., vol. 103, no. C4, pp. 7931-7977, 1998.

[10] TX-GS-DD-3307, Issue 1.3 TerraSAR-X Ground Segment, Level1b Product Format Specification, 2007.

[11] S. Lehner, J. Schulz-Stellenfleth, S. Brusch, and X.-M. Li, "Use of TerraSAR-X data for oceanography," in Proc. EUSAR, Friedrichshafen, Germany, 2008. 
[12] D. W. S. Lodge, "Surface expressions of bathymetry on SEASAT synthetic aperture radar images," Int. J. Remote Sens., vol. 4, no. 3, pp. 639-653, 1983.

[13] D. E. Irvine and D. G. Tilley, "Ocean wave directional spectra and wavecurrent interaction in the Agulhas from the Shuttle Imaging Radar-B synthetic aperture radar," J. Geophys. Res., vol. 93, no. C12, pp. 1538915 401, Dec. 1998

[14] X.-F. Li, W. G. Pichel, M. He, S. Y. Wu, K. S. Friedman, P. ClementeColon, and C. Zhao, "Observation of hurricane-generated ocean swell refraction at the Gulf Stream north wall with the RADARSAT-1 synthetic aperture radar," IEEE Trans. Geosci. Remote Sens., vol. 40, no. 10, pp. 2131-2142, Oct. 2002.

[15] A. K. Liu, P. W. Vachon, and C. Y. Peng, "Observation of wave refraction at an ice edge by synthetic aperture radar," J. Geophys. Res., vol. 96, no. C3, pp. 4803-4808, Mar. 1991.

[16] J. Schulz-Stellenfleth and S. Lehner, "Spaceborne synthetic aperture radar observations of ocean waves traveling into sea ice," J. Geophys. Res., vol. 107, no. C8, p. 3106, Aug. 2002, DOI: 10.1029/2001JC000837.

[17] S. Lehner and Y.-Z. Ren, "Surface wind field retrieval from TerraSAR data," to be published.

[18] W. J. Plant, "Bragg scattering of electromagnetic waves from the air/sea interface," in In Surface Waves and Fluxes, vol. II. Norwell, MA: Kluwer, 1990, pp. 41-108.

[19] A. S. Milman, A. O. Scheffler, and J. R. Bennett, "A theory of the synthetic aperture radar images of time-dependent scenes," J. Geophys. Res., vol. 98, no. C1, pp. 911-925, Jan. 1993.

[20] P. W. Vachon, H. E. Krogstad, and J. S. Paterson, "Airborne and spaceborne synthetic aperture radar observations of ocean waves," Atmos. Ocean, vol. 32, no. 1, pp. 83-112, 1994

[21] V. Kerbaol, B. Chapron, and P. W. Vachon, "Analysis of ERS-1/2 synthetic aperture radar wave mode imagettes," J. Geophys. Res., vol. 103, no. C4, pp. 7833-7846, Apr. 1998.

[22] F. Monaldo, "The influence of altitude and look angle on SAR ocean wave imaging: A practical compromise," in Proc. IGARSS, 1994, vol. 3, pp. 1519-1521.

[23] I. R. Young, W. Rosenthal, and F. Ziemer, "Three-dimensional analysis of marine radar images for the determination of ocean wave directionality and surface currents," J. Geophys. Res., vol. 90, no. C1, pp. 1049-1059, 1985.

[24] J. C. Nieto, G. R. Rodríguez, K. Hessner, and P. I. González, "Inversion of marine radar images for surface wave analysis," J. Atmos. Ocean. Technol., vol. 21, no. 8, pp. 1291-1300, Aug. 2004.

[25] J. C. Nieto, K. Hessner, and K. Reichert, "Estimation of the significant wave height with X-band nautical radars," in Proc. 18th Int. Conf. Offshore Mech. Arctic Eng., St. John's, NF, Canada, 1999.

[26] H. Günther, S. Hasselmann, and P. A. E. M. Janssen, "The WAModel cycle 4 (revised version)," Deutsches Klimarechenzentrum (DKRZ), Hamburg, Germany, 1992.
[27] C. Amante and B. W. Eakins, ETOPO1 1 arc-minute global relief model: Procedures, data sources and analysis. Boulder, CO: Nat. Geophys. Data Center, NOAA, NESDIS, U.S. Dept. Commerce, 2008.

[28] B. Kinsman, Wind Waves: Their Generation and Propagation on the Ocean Surface. Englewood Cliffs, NJ: Prentice-Hall, 1965.

[29] X.-M. Li, S. Lehner, and M.-X. He, "Ocean wave measurements based on satellite synthetic aperture radar (SAR) and numerical wave model (WAM) data-extreme sea state and cross sea analysis," Int. J. Remote Sens., vol. 29, no. 21, pp. 6403-6416, Nov. 2008.

[30] R. S. Arthur, "The effect of islands on surface waves," Bull. Scripps Inst. Oceanogr., vol. 6, no. 1, pp. 1-24, Jun. 1951

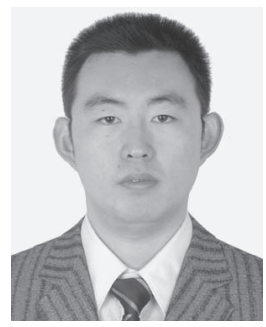

Xiaoming $\mathbf{L i}$ received the B.S. degree in electronic and information engineering from Xi' an Communication College of the PLA in 2002 and the (equivalent) M.S. degree, with work focusing on satellite ocean remote sensing, from the Ocean University of China, Qingdao, China, in 2006. He is currently working toward the Ph.D. degree at the German Aerospace Center (DLR), Wessling, Germany.

His research interests include synthetic aperture radar ocean wave algorithm development, investigation of extremely oceanic weather, and observation of ocean dynamics using spaceborne multisensors.

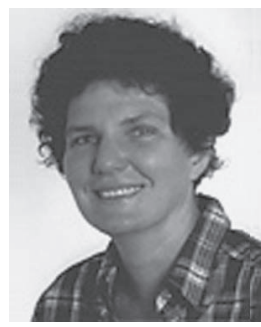

Susanne Lehner received the M.Sc. degree in applied mathematics from Brunel University, Uxbridge, U.K., in 1979 and the Ph.D. degree in geophysics from the University of Hamburg, Hamburg, Germany, in 1984.

She was a Research Scientist with Max-Planck Institute for Climatology, Hamburg. In 1996, she joined the German Aerospace Center (DLR), German Remote Sensing Data Center, Wessling, Germany. Currently, she is a Research Scientist in marine remote sensing with the Remote Sensing Technology Institute, DLR, working on the development of algorithms determining marine parameters from synthetic aperture radar.

Wolfgang Rosenthal, photograph and biography not available at the time of publication. 